\title{
Anaemia, prenatal iron use, and risk of adverse pregnancy outcomes: systematic review and meta-analysis
}

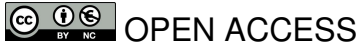

\author{
Batool A Haider $S c D$ candidate ${ }^{1}$, Ibironke Olofin $S c D$ candidate $^{2}$, Molin Wang assistant professor ${ }^{3}$, \\ Donna Spiegelman professor ${ }^{4}$, Majid Ezzati professor ${ }^{5}$, Wafaie W Fawzi professor ${ }^{6}$, on behalf of \\ Nutrition Impact Model Study Group (anaemia)
}

${ }^{1}$ Departments of Epidemiology and Nutrition, Harvard School of Public Health, 677 Huntington Avenue, Boston, MA 02115, USA ; ${ }^{2}$ Department of Epidemiology, Harvard School of Public Health, Boston, MA 02115, USA ; ${ }^{3}$ Department of Medicine, Harvard Medical School, and Departments of Epidemiology and Biostatistics, Harvard School of Public Health, Boston, MA 02115, USA ; ${ }^{4}$ Departments of Epidemiology and Biostatistics, Harvard School of Public Health, Boston, MA 02115, USA ; ${ }^{\mathrm{M} R C-H P A}$ Centre for Environment and Health, Department of Epidemiology and Biostatistics, School of Public Health, Imperial College London, London SW7 2AZ, UK ; ${ }^{6}$ Departments of Global Health and Population, Nutrition and Epidemiology, Harvard School of Public Health, Boston, MA 02115, USA

\begin{abstract}
Objectives To summarise evidence on the associations of maternal anaemia and prenatal iron use with maternal haematological and adverse pregnancy outcomes; and to evaluate potential exposure-response relations of dose of iron, duration of use, and haemoglobin concentration in prenatal period with pregnancy outcomes.

Design Systematic review and meta-analysis

Data sources Searches of PubMed and Embase for studies published up to May 2012 and references of review articles.

Study selection criteria Randomised trials of prenatal iron use and prospective cohort studies of prenatal anaemia; cross sectional and case-control studies were excluded.

Results 48 randomised trials ( 17793 women) and 44 cohort studies ( 1 851682 women) were included. Iron use increased maternal mean haemoglobin concentration by 4.59 (95\% confidence interval 3.72 to 5.46) $\mathrm{g} / \mathrm{L}$ compared with controls and significantly reduced the risk of anaemia (relative risk $0.50,0.42$ to 0.59$)$, iron deficiency $(0.59,0.46$ to $0.79)$, iron deficiency anaemia $(0.40,0.26$ to 0.60$)$, and low birth weight $(0.81,0.71$ to 0.93$)$. The effect of iron on preterm birth was not significant (relative risk $0.84,0.68$ to 1.03 ). Analysis of cohort studies showed a significantly higher risk of low birth weight (adjusted odds ratio 1.29, 1.09 to 1.53$)$ and preterm birth $(1.21,1.13$ to 1.30$)$ with anaemia in the first or second trimester. Exposure-response analysis indicated that for every $10 \mathrm{mg}$ increase in iron dose/day, up to $66 \mathrm{mg} /$ day, the relative risk of maternal anaemia was 0.88 (0.84 to 0.92) ( $P$ for linear trend $<0.001)$.
\end{abstract}

Birth weight increased by 15.1 (6.0 to 24.2) $\mathrm{g}(\mathrm{P}$ for linear trend=0.005) and risk of low birth weight decreased by $3 \%$ (relative risk $0.97,0.95$ to 0.98 ) for every $10 \mathrm{mg}$ increase in dose/day ( $P$ for linear trend<0.001). Duration of use was not significantly associated with the outcomes after adjustment for dose. Furthermore, for each $1 \mathrm{~g} / \mathrm{L}$ increase in mean haemoglobin, birth weight increased by 14.0 (6.8 to 21.8) g ( $P$ for linear trend=0.002); however, mean haemoglobin was not associated with the risk of low birth weight and preterm birth. No evidence of a significant effect on duration of gestation, small for gestational age births, and birth length was noted.

Conclusions Daily prenatal use of iron substantially improved birth weight in a linear dose-response fashion, probably leading to a reduction in risk of low birth weight. An improvement in prenatal mean haemoglobin concentration linearly increased birth weight.

\section{Introduction}

Iron deficiency is the most widespread nutritional deficiency in the world. ${ }^{12}$ It is the most common cause of anaemia during pregnancy. Other causes include parasitic diseases such as malaria, hookworm infections, and schistosomiasis; micronutrient deficiencies including folic acid, vitamin A, and vitamin B12; and genetically inherited haemoglobinopathies such as thalassaemia. ${ }^{3}$ According to the Nutrition Impact Model Study's 2011 estimates, the worldwide prevalence of anaemia in pregnant women was 38\% (95\% confidence interval $33 \%$ to $43 \%$ ), translating into 32 (28 to 36 ) million pregnant women 
globally. ${ }^{4}$ Because of the persistently high burden of disease, the World Health Organization has long recommended the prenatal use of iron supplements in low and middle income countries, and this is also recommended in many high income countries. $^{156}$

In 2011 more than $50 \%$ of anaemia in pregnant women was due to iron deficiency in regions where fewer other causes were present. ${ }^{4}$ Multiple observational studies on prenatal anaemia and only a few on iron deficiency anaemia are available. ${ }^{7}$ One of the main reasons is the use of haemoglobin concentration as a proxy for iron deficiency anaemia due to its low cost and relative ease of determination. Reviews of observational studies show an association between prenatal anaemia and risk of preterm birth, but evidence for other outcomes is inconsistent. ${ }^{9-11}$ Clinical trials of prenatal iron supplementation have shown improvement in haemoglobin concentration, but evidence of an effect on birth outcomes has been found to be inconclusive. ${ }^{12} 13$ The Cochrane review on prenatal iron supplementation found no evidence of a reduction in risk of low birth weight and preterm birth, ${ }^{12}$ whereas Imdad et al showed a reduction in risk of low birth weight only. ${ }^{14}$ Because of the conflicting findings from reviews of observational studies and randomised trials, we have done a comprehensive systematic review evaluating all evidence by collating data from randomised trials and prospective cohort studies in one report. Furthermore, to the best of our knowledge, no systematic evaluation has been done of exposure-response relations of iron dose and haemoglobin concentration in the prenatal period with adverse birth outcomes, identification of which would prove critical to the efforts to reduce this burden.

We did a meta-analysis of randomised trials of the overall effect of use of iron, with or without folic acid, on maternal haematological status, morbidity, and birth outcomes and evaluated the existence and shape, whether linear or non-linear, of the iron dose-response relation with risk of maternal anaemia, birth weight, and risk of low birth weight and preterm birth. Because a greater proportion of women in low and middle income countries seek antenatal care late in pregnancy, we also evaluated the relation of these outcomes with the duration of iron use. As cohort studies often have larger sample sizes and are more likely to have measured baseline haemoglobin, we then summarized evidence from prospective cohort studies by doing a meta-analysis examining the association of prenatal anaemia with birth outcomes. Finally, we assessed

exposure-response relations of haemoglobin concentration with birth weight and risk of low birth weight and preterm birth by using data from trials with haemoglobin measurement and cohort studies, and we compared the magnitude of these associations.

\section{Methods}

We followed the Cochrane Collaboration's method for this review. ${ }^{15}$ We did comprehensive, systematic literature searches of PubMed (from 1966 to 31 May 2012), and Embase (from 1974 to 31 May 2012). We developed separate search strategies consisting of a combination of free text words (tw), words in titles/abstracts (tiab), and medical subject headings (mesh) for exposure, participants, and study design; we then combined these by using "AND" (see box). We placed no language or publication restrictions. We adapted the PubMed search strategy for Embase. We screened reference lists of identified studies and published reviews for additional studies.

\section{Study selection}

Two reviewers (BAH and IO) independently screened titles and abstracts. They then critically reviewed full texts of selected studies to assess eligibility. Any discrepancy between the reviewers was resolved through discussion.

We included randomised trials in pregnant women of daily oral iron or iron and folic acid use compared with placebo, no iron, or no iron and folic acid. We included trials of both supplementation and fortification. We excluded trials of multiple vitamins and minerals, except those that examined the additional effect of iron or iron with folic acid in which all treatment groups received similar vitamins and minerals (except for iron or iron and folic acid). We included trials examining maternal haematological, morbidity, and birth outcomes. Maternal haematological outcomes included mean haemoglobin concentration $(\mathrm{g} / \mathrm{L})$, anaemia (defined as haemoglobin $<110$ $\mathrm{g} / \mathrm{L}$ ), iron deficiency (defined as serum ferritin $<12 \mu \mathrm{g} / \mathrm{L}$ ), and iron deficiency anaemia (defined as haemoglobin $<110 \mathrm{~g} / \mathrm{L}$ and serum ferritin $<12 \mu \mathrm{g} / \mathrm{L}$ ) in the second or third trimester or at delivery and in the postpartum period. Birth outcomes included mean duration of gestation (weeks), preterm birth (defined as birth of a neonate $<37$ weeks of gestation), mean birth weight (g), low birth weight (defined as birth weight $<2500 \mathrm{~g}$ ), mean birth length $(\mathrm{cm})$, small for gestational age birth (defined as birth weight below the 10th centile of the gestational age and sex), stillbirth (defined as death of a fetus after 28 weeks of gestation), perinatal mortality (defined as deaths including stillbirths and neonatal deaths before 7 days of life), and neonatal mortality (defined as death of a neonate in the first month of life). Other maternal outcomes included gestational diabetes mellitus, infection during pregnancy and postpartum, maternal malaria and parasitaemia, and placental malaria. We placed no limits on gestational age at the time of starting iron or duration of iron use. We included both individual and cluster randomised trials.

For analysis of observational studies, we included prospective cohort studies that allowed examination of the association of baseline anaemia with the above specified birth outcomes. We included studies defining anaemia as haemoglobin $<100 \mathrm{~g} / \mathrm{L}$ to haemoglobin $<115 \mathrm{~g} / \mathrm{L}$. When haemoglobin was not reported but haematocrit was available, we estimated haemoglobin concentrations $(\mathrm{g} / \mathrm{L})$ by dividing haematocrit by 3 and then multiplying by 10 . We excluded cross sectional and case-control studies, as these do not allow assessment of the temporal association between exposure and an outcome. We also excluded trials with a quasi-randomised design owing to the high risk of bias and studies in HIV infected women or those with haemoglobinopathies. We excluded trials evaluating different doses of iron, unless they presented comparison groups that met our eligibility criteria.

\section{Data extraction and synthesis}

Two reviewers (BAH and IO) independently extracted data by using a pilot tested data extraction form. We collected information from each study on study design, setting, participants, exposure, time of assessment of exposure, outcomes, confounders, and measures of association. Exposure details for trials included treatment, dose, gestational age at start, and duration and frequency of iron use; for cohort studies, we recorded definition of anaemia and time of assessment. We extracted raw data and effect estimates (relative risks or odds ratios) with $95 \%$ confidence intervals. We extracted odds ratios from cohort studies; when available in the original publication, we also extracted odds ratios adjusted for the potential 


\section{Search strategy}

\#1 "iron compounds" [mesh] OR "iron" [mesh] OR "hematinics" [mesh] OR "iron" [tiab] OR "ferrous" [tiab] OR "ferric" [tiab] OR "hematinics" [tiab] OR "hematinic" [tiab] OR "haematinic" [tiab] OR "haematinics" [tiab] OR "anemia" [mesh] OR "anaemia" [tiab] OR "anemia" [tiab] OR "haemoglobin" [tiab] OR "hemoglobin" [tiab] OR "ferritin" [tiab]) OR "haematocrit" [tiab] OR " hematocrit"[tiab]

\#2 "Pregnant Women"[mesh] OR "Pregnancy"[mesh] OR pregnan* [tiab] OR "gravid” [tiab] OR "obstetric" [tiab] OR "antenatal" [tiab] OR "antepartum" [tiab] OR gestation* [tiab]

\#3 "Cohort Studies" [mesh] OR "Longitudinal Studies" [mesh] OR "follow up studies" [mesh] OR "prospective studies" [mesh] OR "Case Control Studies" [mesh] OR "Retrospective Studies" [mesh] OR "controlled clinical trial" [pt] OR "randomized controlled trial" [pt] OR "clinical trial" [pt] OR cohort* [tiab] OR "longitudinal" [tiab] OR "prospective" [tiab] OR "retrospective" [tiab] OR "Incidence Studies" [tiab] OR "Incidence Study" [tiab] OR "Concurrent Studies" [tiab] OR "Concurrent Study" [tiab] OR "Follow Up" [tiab] OR random*[tiab] OR trial* [tiab] OR ("case"[tw] AND "control"[tw]) OR "comparative study"[mesh])

\#4 (\#1 AND \#2 AND \#3)

$\# 5$ animals [mesh] NOT (humans [mesh] AND animals [mesh])

\#6 \#4 not \#5

confounders. For trials with multiple intervention groups or varying doses of iron, we extracted data for eligible comparison groups. For cluster randomised trials, we extracted estimates adjusted for the cluster design. We incorporated data such that each participant was included in an analysis only once to avoid unit of analysis error. We assessed each trial's methodological quality by using four criteria — namely, randomisation technique, concealment of allocation, blinding, and loss to follow-up. We categorised each criterion as adequate, inadequate, or unclear. We labelled a trial as high quality if it was rated as adequate for randomisation and allocation concealment plus either blinding or loss to follow-up under $20 \%$. We assessed the methodological quality of cohort studies by comparing crude and adjusted estimates, controlling for the study confounders. Eligible foreign language papers were translated into English; however, 11 foreign language papers could not be translated and were not included (see table supplement for references ${ }^{\mathrm{w} 1-11}$ ). We actively contacted study authors to seek clarifications and request missing or additional data or reanalysis, if needed. Discrepancies between the reviewers were resolved through discussion, by contacting the authors, or by consultation with a third reviewer (WWF or ME).

\section{Statistical analysis}

We used fixed effects (Mantel-Haenszel method ${ }^{1617}$ ) and random effects (DerSimonian and Laird method ${ }^{18}$ ) models to calculate summary estimates for the overall effect of iron, with or without folic acid, followed by separate meta-analyses for the effects of iron alone and iron with folic acid. We present summary effects as relative risks for binary outcomes and as mean differences for continuous outcomes, with their respective $95 \%$ confidence intervals. To study the effect of methodological quality of trials, we did sensitivity analyses using data from high quality trials only. We did meta-analyses for outcomes with data for at least five trials or comparison groups.

We assessed presence of between study heterogeneity by using the Q statistic with its $\mathrm{P}$ value and $\mathrm{I}^{2}$ statistics. ${ }^{19}{ }^{20}$ The $\mathrm{I}^{2}$ statistic is used to quantify the proportion of total variation in the effect estimation that is due to between study variation. If the $\mathrm{Q}$ statistic $\mathrm{P}$ value was below 0.10 and $\mathrm{I}^{2}$ exceeded $50 \%$, we considered heterogeneity to be substantial and presented a random effects model. We explored sources of heterogeneity through subgroup and meta-regression analyses, ${ }^{21}$ using the pre-specified subgroups based on trials' characteristics: country category (low or middle income versus high income), ${ }^{22}$ malaria endemicity (endemic versus non-endemic), initial mean haemoglobin concentration (anaemic $(<110 \mathrm{~g} / \mathrm{L})$ versus non-anaemic $(\geq 110 \mathrm{~g} / \mathrm{L}))$, and gestational age at start of treatment (early as $\leq 21$ weeks versus late as $>22$ weeks of gestation). As malaria endemicity was not available for most included studies, we used the malaria atlas project database to characterise endemicity of the study area within a country, ${ }^{23}$ assuming that the endemicity had not changed. Study areas with stable malaria transmission were labelled as endemic, whereas those with unstable transmission or that were risk free were categorised as non-endemic. We further investigated sources of heterogeneity by doing meta-regression analysis and used the residual $\mathrm{I}^{2}$ to estimate residual heterogeneity after adjusting for the characteristic of interest. We assessed publication bias by visual inspection of funnel plots for asymmetry and through Begg's rank correlation and Egger's linear regression tests. ${ }^{24} 25$ We did subgroup analysis and assessments of publication bias for outcomes with 10 or more trials or comparison groups.

We examined the iron dose-response relation with risk of maternal anaemia, low birth weight, and preterm birth by using methods proposed by Greenland et al and Orsini et al, which take into account the correlation between log-relative risk estimates across the exposure categories. ${ }^{26}{ }^{27}$ To evaluate a potential non-linear dose-response relation, we fitted fixed effects restricted cubic spline regression models using four knots at the fifth, 35th, 65th, and 95th centiles of the exposure data and assessed significance of spline variables through hypothesis testing. ${ }^{28}$ For the iron dose-response relation with birth weight, we used a mixed effects meta-regression model to estimate the mean change in birth weight per unit change in iron dose. ${ }^{29} \mathrm{We}$ evaluated non-linearity by using the regression model described above. We also assessed the association with duration of iron use in the above models by adding study specific durations. We assessed the exposure-response relations of mean haemoglobin concentration in the third trimester or at delivery with birth weight and risk of low birth weight and preterm birth by using these statistical methods. We did sensitivity analysis, subgroup analysis, and assessments of publication bias and exposure-response relation only for the overall analysis of iron use, with or without folic acid.

For the meta-analysis of cohort studies, we used odds ratios or mean differences to calculate summary measures. We did a separate meta-analysis for cohort studies to study the association of baseline haemoglobin with the outcomes and to assess whether the findings from cohorts and trials were consistent. We did sensitivity analysis by analysing study specific crude odds ratios and adjusted odds ratios separately and comparing the summary estimates to establish the effect of adjustment for confounders. We assessed presence of between study heterogeneity by using the methods described above. We used the following pre-specified study characteristics for subgroup analysis: period of gestation of anaemia assessment (first and second trimester ( $<27$ weeks of gestation) versus third trimester ( $\geq 27$ weeks)), country category, and malaria endemicity. We used funnel plots and Harbord's test to assess publication bias. ${ }^{30}$ 
We did not use Egger's test owing to the statistical problem of standard error of log odds ratio being mathematically linked to the size of log odds ratio, even in the absence of small study effects. For the exposure-response analysis of haemoglobin concentration on birth weight, low birth weight, and preterm birth, mean haemoglobin concentrations for the anaemic and non-anaemic groups were not available for all cohort studies. To evaluate this relation, we selected a country from each high, middle, and low income countries category and used their mean haemoglobin concentrations for studies with missing values. We selected studies in Hong Kong, China, and HIV negative women in Tanzania for high income, middle income, and low income categories. We used the statistical methods described above to evaluate the exposure-response relations.

We used Stata (version 10.1), SAS (version 9.2), and RevMan (version 5.1) for the analyses. Statistical significance was defined at the 0.05 level.

\section{Results}

\section{Literature search}

Figure $1 \Downarrow$ shows results from the literature search and study selection process. We identified a total of 13668 potentially eligible citations, of which 5882 were from PubMed and 7786 from Embase. Screening of 10821 titles and abstracts after removing duplicates identified 1048 citations for full text review. An additional 12 references were identified from reference lists of previously published reviews. Detailed review of identified full text papers yielded 152 reports of 120 eligible studies, including 62 randomised trials and 58 cohort studies. Of 120 studies, we further excluded 28 studies as data were either missing or presented in a format that precluded inclusion (see table supplement for references ${ }^{\mathrm{w} 12-39}$ ).

\section{Study characteristics}

Supplementary tables 1 and 2 show the characteristics of included trials and cohort studies. Briefly, 17793 pregnant women were included in 48 randomised trials, of which 27 were conducted in high income countries (4861 women) ${ }^{31-57}$ and 21 in low or middle income countries (12 932 women). ${ }^{58-78}$ Thirty four trials compared the effect of daily iron use with no iron or placebo, four trials compared iron with folic acid versus folic acid alone, 14 trials included a comparison of iron with folic acid versus placebo or no treatment, and 10 compared iron with a micronutrient or several micronutrients versus the same set of micronutrients except iron. Two trials evaluated the effect of iron fortification compared with no fortification. ${ }^{47}$ E1 Eighteen trials had adequate randomisation, allocation concealment, and blinding or loss to follow-up under 20\% (supplementary table 1). ${ }^{3132} 36384142454752-5458636670717379$ Only two trials randomised villages or sectors (clusters). ${ }^{58} 74$ The dose of iron in included trials ranged from $10 \mathrm{mg}$ to $240 \mathrm{mg}$ daily; one trial used a daily dose of $900 \mathrm{mg} .{ }^{37}$ Duration of supplementation varied from seven to eight weeks up to 30 weeks during pregnancy. One trial also randomised participants to malaria prophylaxis and another randomised them to anti-helminthic drugs, along with the intervention and control treatment. ${ }^{6370}$

We included 44 cohort studies including 1851682 women. Of these, 22 studies were from high income countries (650 126 women $)^{80-101}$ and 22 were from low or middle income countries (1 201556 women). ${ }^{102-123}$ Anaemia was defined differently in included studies, with definitions ranging from haemoglobin $<100 \mathrm{~g} / \mathrm{L}$ to haemoglobin $<115 \mathrm{~g} / \mathrm{L}$. Studies assessed anaemia at varying times during pregnancy ( 17 measured haemoglobin values in the first or second trimester and nine in the third trimester). Five studies measured concentrations in all three trimesters of pregnancy, in which case we included first trimester values in the analysis. Eight studies used values measured at the first antenatal visit, whereas in 10 studies the time of assessment of anaemia was not specified (supplementary table 2).

\section{Evidence from randomised trials}

We firstly present findings for the overall effect of iron, with or without folic acid, followed by the effect of iron only and iron with folic acid.

\section{Findings for overall effect of iron, with or without folic acid, on haematological outcomes}

Table $1 \Downarrow$ summarises the overall effect of iron on haematological outcomes. We included 36 trials measuring haemoglobin concentration in the third trimester or at delivery and showed a significantly higher mean haemoglobin concentration in the iron, with or without folic acid, group (mean difference 4.59 $\mathrm{g} / \mathrm{L}, 95 \%$ confidence interval 3.72 to 5.46 ; 36 trials; fig $2 \Downarrow$ ). We found no heterogeneity associated with this analysis $\left(\mathrm{I}^{2}=0 \%\right.$; $\mathrm{P}>0.05)$. The funnel plot did not suggest evidence of publication bias (fig $3 \Downarrow$ ), whereas Egger and Begg tests were significant (both $\mathrm{P}<0.05$ ). We found the effect of iron on the postpartum haemoglobin concentration to be significant, whereas that on the second trimester haemoglobin concentration was non-significant (supplementary figures 1 and 2). The effect of intervention on maternal anaemia was assessed in 21 trials. Use of iron, with or without folic acid, led to $50 \%$ reduction in risk of anaemia in the third trimester or at delivery (relative risk $0.50,0.42$ to $0.59 ; 19$ trials; table $1 \Downarrow$, supplementary figure 3 ). Heterogeneity was significant, and results should be interpreted with caution $\left(\mathrm{P}<0.001 ; \mathrm{I}^{2}=83 \%\right)$. A visual inspection of the forest plot indicated that heterogeneity could be due to variation in the degree of difference in effect rather than the direction. The funnel plot and Begg and Egger tests (both $\mathrm{P}<0.05$ ) suggested publication bias (supplementary figure 4 ). Effects on the second trimester or postpartum concentrations could not be evaluated owing to the small number of trials (less than five).

Because haemoglobin concentration is an important indicator of maternal health, we did subgroup analysis to study the effects in various pre-specified subgroups. Mean haemoglobin concentration in the third trimester or at delivery was significantly higher in the low or middle income country category than in the high income category (test $\mathrm{P}=0.003$ ) and for initial mean haemoglobin concentrations $<110 \mathrm{~g} / \mathrm{L}$ versus $\geq 110 \mathrm{~g} / \mathrm{L}$ (test $\mathrm{P}=0.005$ ) (table $2 \Downarrow$ ). We identified no significant difference for malaria endemicity and time of start of iron use in subgroups (both test $\mathrm{P}>0.05$ ). Meta-regression analyses for maternal anaemia showed that the effects were significantly larger in the high income country category (test $\mathrm{P}=0.009$ ), with initial mean haemoglobin concentration $\geq 110 \mathrm{~g} / \mathrm{L}$ (test $\mathrm{P}=0.008$ ), and in malaria non-endemic regions (test $\mathrm{P}=0.003$ ). Adjusting for these covariates independently in meta-regression did not explain heterogeneity substantially (table $3 \Downarrow$ ).

Use of iron, with or without folic acid, also provided significant improvements in iron indicators in the third trimester or at delivery; analysis showed significant reductions in the risk of iron deficiency (relative risk $0.59,0.44$ to $0.79 ; \mathrm{I}^{2}=79 \%$; eight trials) and iron deficiency anaemia $\left(0.40,0.26\right.$ to $0.60 ; \mathrm{I}^{2}=33 \%$; six trials) (table $1 \Downarrow$; supplementary figures 5 and 6 ). Sources of heterogeneity for iron deficiency could not be evaluated owing to the small number of available trials. 


\section{Findings for overall effect of iron, with or without folic acid, on birth outcomes}

Analysis showed a significantly higher mean birth weight in the iron group compared with the control group (mean difference 41.2 (1.2 to 81.2$) \mathrm{g}$; $\mathrm{I}^{2}=99 \%$; 19 trials; table $1 \Downarrow$, supplementary figure 7). Analysis of the high quality trials alone also indicated a significant effect (mean difference 68.7 (37.7 to 99.7) g; $\mathrm{I}^{2}=97 \% ; 12$ trials). Heterogeneity was high, but subgroup analysis and meta-regression showed that birth weights were not significantly different in subgroups (test $\mathrm{P}>0.05$ ). Iron use led to a reduction of $19 \%$ in risk of low birth weight (relative risk $0.81,0.71$ to $0.93 ; \mathrm{I}^{2}=1 \% ; 13$ trials; table $1 \Downarrow$, fig $4 \Downarrow$ ). The analysis of the high quality trials alone found similar results (table $1 \Downarrow$ ). The funnel plot and Begg and Egger tests for low birth weight and for birth weight suggested no evidence of publication bias (all $\mathrm{P}>0.05$ ); however, the funnel plot for birth weight indicated some asymmetry.

Use of iron did not have a significant effect on preterm birth, duration of gestation, small for gestational age births, and birth length ( $\mathrm{P}>0.05$ ) (table $1 \Downarrow$; supplementary figures 8-11).

Sensitivity analyses found similar effects among the high quality trials. The funnel plot and Egger and Begg tests (both $\mathrm{P}>0.05$ ) for preterm birth did not suggest the presence of publication bias. A small number of trials reported effects on stillbirths $(n=3)$, perinatal mortality $(n=4)$, neonatal mortality $(n=3)$, and maternal morbidity outcomes such as gestational diabetes $(\mathrm{n}=1)$, infection during pregnancy $(n=2)$, puerperal sepsis $(n=2)$, and malaria indicators $(n=2)$, precluding further analyses for these outcomes.

\section{Exposure-response relation of iron dose with haematological and birth outcomes}

We noted a significant non-linear, inverse relation between dose of iron and risk of maternal anaemia in the third trimester or at delivery (non-linear test $\mathrm{P}<0.001 ; 18$ trials; table $4 \Downarrow$;

supplementary figure 12). The relation did not change when we excluded the trial that used $900 \mathrm{mg}$ of iron daily ${ }^{37}$ (non-linear test $\mathrm{P}<0.001 ; 17$ trials; table $4 \Downarrow$ ). Because the iron dose recommended is either $60 \mathrm{mg}$ or lower, ${ }^{124}{ }^{125}$ we restricted analysis to trials providing up to $66 \mathrm{mg}$ iron/day to see if giving $60 \mathrm{mg}$ daily has any benefit over lower doses. For a $10 \mathrm{mg}$ increase in iron dose per day, the relative risk of anaemia was 0.88 ( 0.84 to 0.92 ; P for linear trend $<0.001 ; 11$ trials; table $4 \Downarrow$; supplementary figure 13). We used duration data from trials to evaluate the association of duration of use with anaemia; duration of use, adjusted for dose of iron, was not associated with anaemia $(\mathrm{P}>0.05)$.

Analysis of the exposure-response relation between iron dose and birth weight found an increase of 15.1 (6.0 to 24.2) $\mathrm{g}$ in birth weight for every $10 \mathrm{mg}$ increase in daily iron dose $(\mathrm{P}=0.005 ; 18$ trials; table $4 \Downarrow)$. Similarly, risk of low birth weight decreased by $3 \%$ for every $10 \mathrm{mg}$ increase in daily iron dose (relative risk 0.97, 0.95 to 0.98 ; $\mathrm{P}$ for linear trend<0.001; 13 trials; table $4 \Downarrow$ ). We found no evidence of a non-linear association with either birth weight or low birth weight (both $\mathrm{P}>0.05$ ). When we restricted analyses to trials using up to 66 $\mathrm{mg}$ /day iron, findings for low birth weight did not change (table $4 \Downarrow$; supplementary figure 14); however, we found evidence of non-linearity for birth weight $(\mathrm{P}<0.001 ; 14$ trials; supplementary figure 15). Duration of iron use was not significantly associated with either outcome, after adjustment for dose. Iron dose was not associated with risk of preterm birth (relative risk 0.99, 0.95 to 1.04 ; $\mathrm{P}$ for linear trend $=0.67 ; 12$ trials; table $4 \Downarrow$ ).

\section{Exposure-response relation of haemoglobin concentration with birth outcomes}

A unit increase in mean haemoglobin concentration in the third trimester or at delivery linearly increased birth weight by 14.0 (6.8 to 21.8$) \mathrm{g}(\mathrm{P}=0.002 ; 16$ trials; table $5 \Downarrow)$. We found no evidence of a non-linear association $(\mathrm{P}>0.05$; supplementary figure 16). However, the effect on risk of low birth weight was non-significant (relative risk $0.96,0.84$ to 1.09 ; $\mathrm{P}$ for linear trend $=0.21 ; 11$ trials; table $5 \Downarrow$, supplementary figure 17 ). Similarly, the effect on risk of preterm birth was also non-significant (relative risk 0.99, 0.94 to 1.04; P for linear trend $=0.70$; eight trials; table $5 \Downarrow$, supplementary figure 18).

\section{Findings for effect of iron only versus no iron/placebo on haematological and birth outcomes}

Use of iron was associated with significantly increased mean haemoglobin concentration in the third trimester or at delivery (mean difference 4.50 (3.62 to 5.39) g/L; $\mathrm{I}^{2}=0 \% ; 31$ trials; supplementary figure 19) and in the postpartum period (7.01 ( 0.36 to 13.66 ) g/L; $\mathrm{I}^{2}=0 \%$; eight trials; supplementary figure 20) compared with no iron or placebo. Similar to the overall analysis, we found significant reductions in the risk of anaemia (relative risk $0.56,0.48$ to $0.65 ; \mathrm{I}^{2}=75 \% ; 17$ trials), iron deficiency $\left(0.59,0.44\right.$ to $0.79 ; \mathrm{I}^{2}=79 \%$; eight trials), and iron deficiency anaemia $\left(0.37,0.23\right.$ to $0.60 ; \mathrm{I}^{2}=47 \%$; five trials) (supplementary figures 21-23). Heterogeneity was significant, and findings should be interpreted with caution. However, visual inspection of the forest plots indicated that heterogeneity seemed to be due to the variation in effects sizes, rather than the direction of the effect. Use of iron was associated with a significant increase in birth weight (mean difference $40.8(0.97$ to 80.6$) \mathrm{g} ; \mathrm{I}^{2}=99 \%$; 16 trials) and reduction in risk of low birth weight (relative risk $0.81,0.71$ to $0.91 ; \mathrm{I}^{2}=9 \% ; 10$ trials). Effects on duration of gestation (mean difference 0.11 ( -0.35 to 0.57 ) weeks; nine trials), preterm birth (relative risk $0.92,0.80$ to 1.07; 10 trials), small for gestational age births (relative risk $0.84,0.66$ to 1.07 ; six trials), and birth length (mean difference $-0.93(-4.76$ to 2.90$) \mathrm{cm}$; seven trials) were not significant (supplementary figures 24-29)

\section{Findings for effect of iron with folic acid versus no iron and folic acid/placebo on haematological and birth outcomes}

Iron with folic acid was associated with a significant increase in mean haemoglobin concentration (mean difference 10.41 ( 5.36 to 15.46$) \mathrm{g} / \mathrm{L} ; \mathrm{I}^{2}=0 \%$; nine trials) and reduction in risk of anaemia in the third trimester or at delivery (relative risk 0.44 , 0.37 to $0.53 ; \mathrm{I}^{2}=44 \%$; five trials) (supplementary figures 30 and 31). Effects on other haematological and pregnancy outcomes could not be evaluated owing to the small number of available trials (less than five).

\section{Evidence from cohort studies}

\section{Association between anaemia and birth outcomes}

Table $6 \Downarrow$ summarises the association between prenatal anaemia, irrespective of the time of assessment, and birth outcomes. Prenatal anaemia significantly increased the risk of low birth weight compared with no anaemia (crude odds ratio 1.25, 1.08 to $1.45 ; \mathrm{I}^{2}=90 \% ; 25$ studies); however, the association was non-significant when we pooled adjusted estimates extracted from the included studies (adjusted odds ratio 1.13, 0.94 to 1.35; $\mathrm{I}^{2}=86 \%$; nine studies) (supplementary figures 32 and 33 ). We noted a significantly higher risk of preterm birth in the anaemic 
group (crude odds ratio $1.28,1.12$ to $1.47 ; \mathrm{I}^{2}=89 \% ; 26$ studies). This association remained significant when we pooled adjusted estimates (adjusted odds ratio $1.28,1.11$ to $1.48 ; \mathrm{I}^{2}=83 \% ; 13$ studies) (supplementary figures 34 and 35 ). We found a significantly higher risk of stillbirth in the anaemic group (crude odds ratio $1.19,1.09$ to $1.29 ; \mathrm{I}^{2}=24 \% ; 12$ studies; supplementary figure 36); however, adjusted estimates could not be pooled because only two studies presented them. Anaemia was marginally associated with the duration of gestation $(\mathrm{P}=0.05)$ but not with birth weight; associations with small for gestational age births and perinatal mortality were not significant $(\mathrm{P}>0.05)$ (supplementary figures 37-41). Associations with birth length and neonatal mortality could not be evaluated owing to paucity of data.

We found significant heterogeneity in the preterm birth and low birth weight analyses. Subgroup analysis found a significantly higher risk of preterm birth with first or second trimester anaemia (adjusted odds ratio $1.21,1.13$ to $1.30 ; \mathrm{I}^{2}=0 \%$; seven studies) but not with third trimester anaemia (adjusted odds ratio $1.20,0.80$ to $1.79 ; \mathrm{I}^{2}=90 \%$; six studies) (test $\mathrm{P}=0.71$ ) (supplementary table 3 ). We found no significant difference for subgroups of country category (high (adjusted odds ratio 1.26, 1.02 to $1.57 ; \mathrm{I}^{2}=87 \%$; nine studies) versus low or middle income countries (adjusted odds ratio 1.30, 1.05 to $1.61 ; \mathrm{I}^{2}=77 \%$; five studies) (test $\mathrm{P}=0.83$ ) (supplementary table 3 ). We could not do subgroup analysis for malaria endemicity owing to the small number of studies in one of the subgroups. Supplementary table 4 presents findings for the low birth weight subgroup analysis, which showed significantly higher risk with first or second trimester anaemia (adjusted odds ratio 1.29, 1.09 to 1.53; $\mathrm{I}^{2}=82 \%$; six studies) and no significant associations in subgroups of high income countries (adjusted odds ratio 1.21, 0.95 to 1.53; $\mathrm{I}^{2}=90 \%$; six studies) or malaria non-endemic countries (adjusted odds ratio $1.13,0.94$ to $1.35 ; \mathrm{I}^{2}=86 \%$; nine studies); however, we could not calculate $P$ values for subgroup differences owing to the small number of studies in one of the subgroups. Funnel plots and Harbord tests for low birth weight and preterm birth (both $\mathrm{P}>0.05$ ) did not suggest any evidence of publication bias.

\section{Exposure- response relation of haemoglobin concentration with birth outcomes}

Analysis of the cohort studies showed non-significance of the exposure-response relation between mean haemoglobin concentration and birth weight (mean difference 3.2 ( -17.9 to 24.3) g; $\mathrm{P}=0.77$; nine studies; supplementary table 5). More studies assessed the association with low birth weight, and the association was significant although the magnitude was small (relative risk 0.99, 0.98 to 0.99; P for linear trend<0.001; 25 studies; supplementary table 5). We also found the exposure-response relation of mean haemoglobin concentration in the first or second trimester with risk of preterm birth to be significant (relative risk 0.98, 0.98 to 0.99 ; $\mathrm{P}$ for linear trend $<0.001 ; 12$ studies; supplementary table 5).

\section{Discussion}

In meta-analyses of randomised trials of prenatal iron use, we found evidence of significant reductions in maternal anaemia, iron deficiency, iron deficiency anaemia, and risk of low birth weight. Dose-response analysis showed a linear decrease in maternal anaemia with higher doses of iron, up to $66 \mathrm{mg} /$ day. Higher doses of iron were associated with a linear increase in birth weight and decrease in risk of low birth weight. With iron up to $66 \mathrm{mg} /$ day, we found a non-linear association with birth weight but a linear reduction in risk of low birth weight.
Furthermore, higher mean haemoglobin concentration in the prenatal period linearly increased birth weight with a dose-response relation. We did not find any evidence of reduction in risk of preterm birth as a result of iron use; however, meta-analysis of cohort studies indicated a higher risk of preterm birth with first or second trimester anaemia and with lower mean haemoglobin concentration.

\section{Strengths of meta-analysis in relation to other meta-analyses}

This meta-analysis is a comprehensive evaluation of the evidence, incorporating randomised trials and cohort studies, with examination of associations with haematological, morbidity, and birth outcomes in one report. To the best of our knowledge, this is the first meta-analysis to examine the exposure-response relation of dose of iron, duration of use, and haemoglobin concentration on birth weight and risk of low birth weight and preterm birth. We made various comparisons evaluating the overall effect of iron, iron only, and iron with folic acid. We made an effort to extract all available data from trials, especially those with multiple comparison groups. In addition, we evaluated effects in various predefined subgroups and did meta-regression to evaluate sources of heterogeneity. We also did sensitivity analysis to assess the effect of the methodological quality of trials on effect estimates.

\section{Results in relation to other meta-analyses}

Our findings of significant improvement in maternal haematological outcomes as a result of iron use corroborate those of previous reviews. ${ }^{12} 14126127$ We noted a greater effect on haemoglobin concentration in low or middle income countries and with lower initial mean haemoglobin concentration $(<110$ $\mathrm{g} / \mathrm{L}$ ). We showed a positive, linear dose-response relation between iron dose up to $66 \mathrm{mg}$ daily and risk of maternal anaemia, indicating a benefit of giving higher rather than lower doses over this range. These findings are biologically plausible, as several mechanisms regulating intestinal iron absorption have been identified..$^{72}{ }^{129}$ Human studies and animal models have shown that depleted body iron stores enhance absorptive capacity in the duodenum, which is increased several-fold in the presence of iron deficiency. Another important regulator is bone marrow erythropoiesis, which adjusts intestinal absorption in response to the erythropoietic demands. Review of epidemiological studies shows that women in low or middle income countries generally enter pregnancy with more limited iron stores and lower haemoglobin concentrations than do those in high income countries. An increasing demand for iron in these women may thus enhance intestinal absorption to a greater extent, resulting in a greater haematological response. Improved haematological status during pregnancy may also reduce the mortality risk in women with antepartum or postpartum haemorrhage and lead to improved iron status in the postpartum period. $^{911}$

We found a significant reduction in the risk of low birth weight as a result of iron use, which is similar to the finding of Imdad et al. ${ }^{130}$ This, however, is in contrast to that of the Cochrane review, ${ }^{12}$ which did not find evidence of a decreased risk. We present below a brief description of the methodological differences between the various meta-analyses. The Cochrane review included 45 randomised and quasi-randomised trials identified up to March 2009 and found no significant effect on birth weight, low birth weight, preterm birth, and small for gestational age births. ${ }^{12} \mathrm{We}$, in this meta-analysis, included larger number of randomised trials with searches updated to 31 May 2012. We excluded quasi-randomised trials, as these have 
a high risk of bias owing to the inadequate method of random sequence generation or allocation concealment. The differences in the eligibility criteria for selecting studies between the two reviews and the dates of literature search led to a different set of trials being analysed in the two reviews. Imdad et al evaluated a smaller set of outcomes and identified 30 randomised and quasi-randomised trials up to June $2011 .{ }^{130}$ The analyses were associated with significant heterogeneity, but the sources of heterogeneity were not examined using study characteristics. Yakoob et al and Sloan et al included randomised and quasi-randomised trials evaluating effects on haematological outcomes only. ${ }^{126}{ }^{127}$ None of the earlier reviews did meta-regression to evaluate sources of heterogeneity or an assessment of exposure-response relations, which were objectives of our meta-analysis.

The dose-response analysis showed a linear increase in birth weight with higher iron doses. More importantly, higher mean haemoglobin concentration linearly increased birth weight. These results indicate that for every $10 \mathrm{~g} / \mathrm{L}$ increase in mean haemoglobin concentration in the third trimester or at delivery, the birth weight would increase by 143 (95\% confidence interval 68 to 218$) \mathrm{g}$. The dose of iron recommended by WHO is 60 $\mathrm{mg} /$ day, whereas the Institute of Medicine has set the tolerable upper intake level as $45 \mathrm{mg}$ /day owing to the gastrointestinal side effects with higher doses. ${ }^{124}{ }^{125}$ Trials comparing various doses of iron have been done and indicate a larger improvement in iron status with higher doses, but no difference in anaemia and other clinical outcomes was noted. ${ }^{131}{ }^{132}$ We also showed a reduction in risk of low birth weight with higher iron doses and identified a similar relation with iron dose up to $66 \mathrm{mg} / \mathrm{day}$. An increase in birth weight of the magnitude specified above could prove critical for the survival of neonates born with birth weights in the lower range. ${ }^{133}$ Recent literature also provides insight into the biological mechanisms that could potentially explain the effects on birth weight. A potential role of the placenta in the regulation of iron transfer and the transport proteins involved has been identified. ${ }^{78} 134135$ Animal models also indicate a role of fetal liver iron stores in regulating iron absorption through the placenta. ${ }^{135}{ }^{136}$ In contrast to the significant effect on birth weight from trials, this meta-analysis of cohort studies did not indicate a significant increase in birth weight with increasing haemoglobin concentration. Several reasons for this observation are possible. Firstly, as the data used in this analysis were observational in nature, confounding of the association could have occurred. Secondly, as the mean haemoglobin concentrations for most studies were missing, we assumed that countries within the same category would have similar mean haemoglobin concentrations. Under that assumption, we used similar values for all countries in low, middle, or high income categories, which may not have been completely accurate.

Our analysis of cohort studies showed a significantly increased risk of preterm birth with first or second trimester anaemia. These results are in agreement with previous reviews of observational studies. ${ }^{10}{ }^{11}$ Xiong et al included 10 observational studies published up to 1999 in their review. ${ }^{10}$ Both cohort and case-control studies were included in this review. The Global Burden of Disease Comparative Risk Assessment analysis of iron deficiency anaemia included 10 studies examining association with perinatal mortality outcome. ${ }^{9}$ This review included cross sectional studies examining the association of haemoglobin measured at delivery with pregnancy outcomes, together with other observational designs. Cross sectional and case-control studies do not allow evaluation of the temporal association between the exposure and outcome, and they have high risk of bias. These were, therefore, excluded from our meta-analysis. We also did sensitivity and subgroup analyses and explored exposure-response relations between haemoglobin concentration and birth outcomes, which were not included in earlier reviews of observational studies. Although we found a significant risk of preterm birth in our meta-analysis of cohort studies, the meta-analysis of trials indicated a non-significant effect of iron use on preterm birth risk. It is plausible that causes of anaemia other than iron deficiency are implicated in the pathway; a few have been identified. ${ }^{120}$ Existence of chronic hypoxia may induce a stress response, resulting in production of corticotrophin releasing hormone, elevated concentrations of which have been identified as a major risk factor of preterm birth. Additionally, the risk of preterm birth may increase owing to oxidative damage to erythrocytes and the fetoplacental unit. Lastly, it may increase the risk of infections, stimulating production of corticotrophin releasing hormone and increasing the risk of preterm birth.

A potential concern exists regarding an increased risk of adverse maternal and birth outcomes associated with high haemoglobin concentrations. Several studies have found increased risks of low birth weight, preterm birth, and small for gestational age birth with high maternal haemoglobin concentrations..$^{94} 119137$ The adverse birth outcomes may be comparable to those of anaemia, but the causes may be different. ${ }^{121} 137$ This, however, warrants further investigation and was not a part of our review. The interaction between iron supplementation and susceptibility to infections, including malaria, also remains a concern. Studies of iron supplementation of children in malaria endemic countries suggest that iron supplementation increases the risk of morbidity and mortality among children ${ }^{138}{ }^{139}$; however, studies of antenatal iron use have shown conflicting results for malaria outcomes. ${ }^{68140141}$ We could not evaluate these outcomes in this review owing to the paucity of data.

\section{Limitations of meta-analysis}

Our review has several limitations. Firstly, we could not evaluate associations with several outcomes owing to the paucity of data. These include stillbirths and neonatal and perinatal mortality in iron use meta-analyses and birth length and neonatal mortality in the cohort studies analysis. Secondly, significant heterogeneity existed for several outcomes that could not be explained substantially by our pre-specified subgroups. This limits our understanding of the association in various settings and restricts the generalisability of our findings. Thirdly, a small number of trials had evaluated the effect of iron fortification in pregnant women, so a separate meta-analysis for fortification trials could not be done. Fourthly, although we used adjusted estimates from cohort studies, these results still could have been biased owing to residual confounding, in either direction, depending on the nature of the residual confounding. Finally, as explained earlier, for the exposure-response analysis of cohort studies, we assumed mean haemoglobin concentrations for studies with missing values, which may have introduced bias towards the null due to random measurement error.

\section{Conclusions: implications for practice and future research}

Our findings suggest that use of iron in women during pregnancy may be used as a preventive strategy to improve maternal haematological status and birth weight. Prenatal anaemia and iron deficiency have been identified as one of the preventable risk factors for disease with a substantial disease burden. ${ }^{142}$ This calls for a rigorous evaluation of the effectiveness of existing antenatal care programmes in high burden countries to identify gaps in policy and programme implementation. Targeted 
interventions to strengthen the infrastructure of antenatal care should be used. Future research to explore feasible strategies of iron delivery in a country setting and evaluation of the effectiveness of other strategies, such as fortification and dietary diversification, should be done.

We thank Paul Bain at the Countway Library of Medicine, Harvard Medical School, for assistance in the development of search strategy; Ruifeng Li at the Department of Epidemiology, Harvard School of Public Health, for statistical assistance; and Xin Li for research assistance.

Writing Team: Batool A Haider (BAH), Ibironke Olofin (IO), Molin Wang (MW), Donna Spiegelman (DS), and Wafaie W Fawzi (WWF) (Harvard School of Public Health, Boston, MA, USA); Majid Ezzati (ME) (School of Public Health, Imperial College London, London, UK).

Iron Review and Re-analysis Team: Batool A Haider and Ibironke Olofin (Harvard School of Public Health, Boston, MA, USA); Gustavo F Gonzales (GFG) and Vilma Tapia (VT) (Universidad Peruana Cayetano Heredia, Lima, Peru); Aiguo Ren (AR) and Juan Wang (JW) (Peking University Health Science Center, Beijing, China).

Contributors: WWF, ME, and BAH designed the review. $\mathrm{BAH}$ wrote and implemented the protocol under the guidance of ME and WWF. BAH developed the search strategy and ran searches. BAH and IO screened the studies and extracted data. BAH analysed the data. DS and MW provided statistical guidance. BAH wrote the first draft of the manuscript. $\mathrm{BAH}, \mathrm{WWF}, \mathrm{ME}$, and DS contributed to the interpretation of results and subsequent revisions. All writing team members approved the final version of the manuscript. GFG, VT, AR, and JW reanalysed their cohort study data for inclusion in the review. WWF is the guarantor.

Funding: The Nutrition Impact Model Study was funded by the Bill and Melinda Gates Foundation. Additional support came from the Saving Brains Program, Grand Challenges Canada Grant Number 0073-03. The funding sources had no role in the study design; in the collection, analysis, and interpretation of results; in the writing of the manuscript; or in the submission of the manuscript for publication. No author has any affiliation with the funding agency.

Competing interests: All authors have completed the ICMJE uniform disclosure form at www.icmje.org/coi_disclosure.pdf (available on request from the corresponding author) and declare: no support from any organisation for the submitted work; no financial relationships with any organisations that might have an interest in the submitted work in the previous three years; no other relationships or activities that could appear to have influenced the submitted work.

Ethical approval: Not needed.

Data sharing: No additional data available.

1 Stoltzfus R, Dreyfuss M. Guidelines for the use of iron supplements to prevent and treat iron deficiency anaemia. ILSI Press, 1998.

2 World Health Organization. Micronutrient deficiencies: iron deficiency anaemia. www. who. int/nutrition/topics/ida/en/.

3 World Health Organization. The prevalence of anaemia in women: a tabulation of available information (WHO/MCH/MSM/92). 2nd ed. WHO, Maternal Health and Safe Motherhood Programme, Division of Family Health, 1992.

4 Stevens G, Finucane M, De-Regil L, Paciorek C, Flaxman S, Branca F, et al. Global, regional, and national trends in total and severe anaemia prevalence in children and pregnant and non-pregnant women. Lancet Global Health [forthcoming]

5 Institute of Medicine. Iron deficiency anemia: guidelines for prevention, detection and management among U.S. children and women of childbearing age. National Academy Press, 1993.

6 Centers for Disease Control and Prevention. Recommendations to prevent and control iron deficiency in the United States. MMWR Recomm Rep 1998;47(RR-3):1-29.

7 Scholl T, Hediger M, Fischer R, Shearer J. Anemia vs iron deficiency: increased risk of preterm delivery in a prospective study. Am J Clin Nutr 1992;55:985-8.

8 Brabin B, Ginny M, Sapau J, Galme K, Paino J. Consequences of maternal anaemia on outcome of pregnancy in a malaria endemic area in Papua New Guinea. Ann Trop Med Parasitol 1990;84:11-24.

9 Stoltzfus R, Mullany L, Black R. Iron deficiency anemia. In: Ezzati M, Lopez A, Rodgers $\mathrm{A}$, Murray $\mathrm{C}$, eds. Comparative quantification of health risks: global and regional burden of disease attributable to selected major risk factors. World Health Organization, 2004:163-209

10 Xiong X, Buekens P, Alexander S, Demianczuk N, Wollast E. Anemia during pregnancy and birth outcome: a meta-analysis. Am J Perinatol 2000;17:137-46.

11 Allen LH. Anemia and iron deficiency: effects on pregnancy outcome. Am J Clin Nutr 2000;71(5 suppl):1280-4S
12 Pena-Rosas JP, Viteri FE. Effects and safety of preventive oral iron or iron+folic acid supplementation for women during pregnancy. Cochrane Database Syst Rev 2009;(4):CD004736.

13 Rush D. Nutrition and maternal mortality in the developing world. Am J Clin Nutr 2000;72(1 suppl):212-40S.

14 Imdad A, Bhutta ZA. Routine iron/folate supplementation during pregnancy: effect on maternal anaemia and birth outcomes. Paediatr Perinat Epidemiol 2012;26(suppl 1):168-77.

15 Higgins J, Green S, eds. Cochrane handbook for systematic reviews of interventions version 5.1.0 [updated March 2011]. Cochrane Collaboration, 2011.

16 Greenland S, Robins JM. Estimation of a common effect parameter from sparse follow-up data. Biometrics 1985;41:55-68.

17 Mantel N, Haenszel W. Statistical aspects of the analysis of data from retrospective studies of disease. J Natl Cancer Inst 1959;22:719-48.

18 DerSimonian R, Laird N. Meta-analysis in clinical trials. Control Clin Trials 1986;7:177-88

19 Higgins JP, Thompson SG, Deeks JJ, Altman DG. Measuring inconsistency in meta-analyses. BMJ 2003;327:557-60.

20 Higgins JP, Thompson SG. Quantifying heterogeneity in a meta-analysis. Stat Med 2002;21:1539-58.

21 Thompson SG, Higgins JP. How should meta-regression analyses be undertaken and interpreted? Stat Med 2002;21:1559-73.

22 World Bank. World Bank list of economies. 2012. siteresources.worldbank.org/ DATASTATISTICS/Resources/CLASS.XLS.

23 Malaria Atlas Project. The spatial limits of malaria transmission. 2012. www.map.ox.ac. ukl.

24 Begg CB, Mazumdar M. Operating characteristics of a rank correlation test for publication bias. Biometrics 1994;50:1088-101.

25 Egger M, Davey Smith G, Schneider M, Minder C. Bias in meta-analysis detected by a simple, graphical test. BMJ 1997;315:629-34.

26 Orsini N, Li R, Wolk A, Khudyakov P, Spiegelman D. Meta-analysis for linear and nonlinear dose-response relations: examples, an evaluation of approximations, and software. Am J Epidemiol 2012;175:66-73.

27 Greenland S, Longnecker MP. Methods for trend estimation from summarized dose-response data, with applications to meta-analysis. Am J Epidemiol 1992;135:1301-9.

28 Durrleman S, Simon R. Flexible regression models with cubic splines. Stat Med 1989;8:551-61.

29 Stram DO. Meta-analysis of published data using a linear mixed-effects model. Biometrics 1996;52:536-44.

30 Harbord RM, Egger M, Sterne JA. A modified test for small-study effects in meta-analyses of controlled trials with binary endpoints. Stat Med 2006;25:3443-57.

31 Barton DP, Joy MT, Lappin TR, Afrasiabi M, Morel JG, O'Riordan J, et al. Maternal erythropoietin in singleton pregnancies: a randomized trial on the effect of oral hematinic supplementation. Am J Obstet Gynecol 1994;170:896-901.

32 Bloxam DL, Williams NR, Waskett RJ, Pattinson-Green PM, Morarji Y, Stewart SG. Maternal zinc during oral iron supplementation in pregnancy: a preliminary study. Clin $\mathrm{Sci}$ (Lond) 1989;76:59-65.

33 Butler EB. The effect of iron and folic acid on red cell and plasma volume in pregnancy. J Obstet Gynaecol Br Commonw 1968;75:497-510.

34 Buytaert G, Wallenburg HC, Van Eijck HG, Buytaert P. Iron supplementation during pregancy. Eur J Obstet Gynecol Reprod Biol 1983;15:11-6.

35 Cantlie GS, De Leeuw NK, Lowenstein L. Iron and folate nutrition in a group of private obstetrical patients. Am J Clin Nutr 1971;24:637-41.

36 Chan KK, Chan BC, Lam KF, Tam S, Lao TT. Iron supplement in pregnancy and development of gestational diabetes-a randomised placebo-controlled trial. BJOG 2009;116:789-97, discussion 97-8.

37 Chisholm M. A controlled clinical trial of prophylactic folic acid and iron in pregnancy. $J$ Obstet Gynaecol Br Commonw 1966;73:191-6.

38 Cogswell ME, Parvanta I, Ickes L, Yip R, Brittenham GM. Iron supplementation during pregnancy, anemia, and birth weight: a randomized controlled trial. Am J Clin Nutr 2003;78:773-81.

39 Dawson EB, Albers J, McGanity WJ. Serum zinc changes due to iron supplementation in teen-age pregnancy. Am J Clin Nutr 1989;50:848-52.

40 De Benaze C, Galan P, Wainer R, Hercberg S. [Prevention of iron-deficiency anemia in pregnancy using early iron supplementation: a controlled trial]. Rev Epidemiol Sante Publique 1989;37:109-18.

41 Eskeland B, Malterud K, Ulvik RJ, Hunskaar S. Iron supplementation in pregnancy: is less enough? A randomized, placebo controlled trial of low dose iron supplementation with and without heme iron. Acta Obstet Gynecol Scand 1997;76:822-8.

42 Harvey LJ, Dainty JR, Hollands WJ, Bull VJ, Hoogewerff JA, Foxall RJ, et al. Effect of high-dose iron supplements on fractional zinc absorption and status in pregnant women. Am J Clin Nutr 2007;85:131-6.

43 Holly RG. Anemia in pregnancy. Obstet Gynecol 1955;5:562-9.

44 Lee JI, Lee JA, Lim HS. Effect of time of initiation and dose of prenatal iron and folic acid supplementation on iron and folate nutriture of Korean women during pregnancy. $A m \mathrm{~J}$ Clin Nutr 2005;82:843-9.

45 Makrides M, Crowther CA, Gibson RA, Gibson RS, Skeaff CM. Efficacy and tolerability of low-dose iron supplements during pregnancy: a randomized controlled trial. Am J Clin Nutr 2003;78:145-53.

46 Meier PR, Nickerson HJ, Olson KA, Berg RL, Meyer JA. Prevention of iron deficiency anemia in adolescent and adult pregnancies. Clin Med Res 2003;1:29-36.

47 McKenna D, Spence D, Haggan SE, McCrum E, Dornan JC, Lappin TR. A randomized trial investigating an iron-rich natural mineral water as a prophylaxis against iron deficiency in pregnancy. Clin Lab Haematol 2003:25:99-103.

48 Milman N, Agger AO, Nielsen OJ. Iron supplementation during pregnancy: effect on iron status markers, serum erythropoietin and human placental lactogen. A placebo controlled study in 207 Danish women. Dan Med Bull 1991;38:471-6.

49 Romslo I, Haram K, Sagen N, Augensen K. Iron requirement in normal pregnancy as assessed by serum ferritin, serum transferrin saturation and erythrocyte protoporphyrin determinations. Br J Obstet Gynaecol 1983:90:101-7.

50 Puolakka J JO, Pakarinen A, Jarvinen PA, Vihko R. Serum ferritin as a measure of iron stores during and after normal pregnancy with and without iron supplement. Acta Obstet Gynecol Scand 1980;95:43-51.

51 Pritchard JA, Hunt CF. A comparison of the hematologic responses following the routine prenatal administration of intramuscular and oral iron. Surg Gynecol Obstet 1958;106:516-8. 


\section{What is already known on this topic}

Synthesis of evidence from observational studies indicates an association between prenatal anaemia and risk of preterm birth, but evidence on other birth outcomes is inconsistent

Evidence from randomised trials on the effect of prenatal iron use on adverse birth outcomes is also inconclusive

\section{What this study adds}

This comprehensive meta-analysis of randomised trials suggests that prenatal iron use is associated with a significant increase in birth weight and reduction in risk of low birth weight

A dose-response relation of higher iron dose with increasing birth weight and decreasing risk of low birth weight exists An exposure-response relation also exists between increasing mean haemoglobin concentration in the prenatal period and higher birth weight

52 Siega-Riz AM, Hartzema AG, Turnbull C, Thorp J, McDonald T, Cogswell ME. The effects of prophylactic iron given in prenatal supplements on iron status and birth outcomes: a randomized controlled trial. Am J Obstet Gynecol 2006;194:512-9.

53 Tura S, Carenza L, Baccarani M, Bagnara M, Bocci A, Bottone P, et al. [Therapy and iron supplements with ferritin iron during pregnancy: randomized prospective study of 458 cases]. Recenti Prog Med 1989;80:607-14.

54 Wallenburg $\mathrm{HC}$, van Eijk HG. Effect of oral iron supplementation during pregnancy on maternal and fetal iron status. J Perinat Med 1984;12:7-12.

55 Taylor DJ, Mallen C, McDougall N, Lind T. Effect of iron supplementation on serum ferritin levels during and after pregnancy. Br J Obstet Gynaecol 1982;89:1011-7.

56 Van Eijk HG, Kroos MJ, Hoogendoorn GA, Wallenburg HC. Serum ferritin and iron stores during pregnancy. Clin Chim Acta 1978;83:81-91.

57 Svanberg B, Arvidsson B, Norrby A, Rybo G, Solvell L. Absorption of supplemental iron during pregnancy - a longitudinal study with repeated bone marrow studies and absorption measurements. Acta Obstet Gynecol Scand 1975;48:87-108.

58 Christian P, Khatry SK, Katz J, Pradhan EK, LeClerq SC, Shrestha SR, et al. Effects of alternative maternal micronutrient supplements on low birth weight in rural Nepal: double blind randomised community trial. BMJ 2003:326:571.

59 Charoenlarp P, Dhanamitta S, Kaewvichit R, Silprasert A, Suwanaradd C, Na-Nakorn S, et al. A WHO collaborative study on iron supplementation in Burma and in Thailand. Am $J$ Clin Nutr 1988;47:280-97

60 Batu AT, Toe T, Pe H, Nyunt KK. A prophylactic trial of iron and folic acid supplements in pregnant Burmese women. Isr J Med Sci 1976;12:1410-7.

61 Hoa PT, Khan NC, van Beusekom C, Gross R, Conde WL, Khoi HD. Milk fortified with iron or iron supplementation to improve nutritional status of pregnant women: an intervention trial from rural Vietnam. Food Nutr Bull 2005;26:32-8.

62 Freire WB. Hemoglobin as a predictor of response to iron therapy and its use in screening and prevalence estimates. Am J Clin Nutr 1989;50:1442-9.

63 Fleming AF, Ghatoura GB, Harrison KA, Briggs ND, Dunn DT. The prevention of anaemia in pregnancy in primigravidae in the guinea savanna of Nigeria. Ann Trop Med Parasitol 1986:80:211-33.

64 Ma GA, Schouten EG, Ye Sun Y, Yang F, Xia Han X, Zhi Zhang F, et al. Supplementation of iron alone and combined with vitamins improves haematological status, erythrocyte membrane fluidity and oxidative stress in anaemic pregnant women. Br J Nutr 2010;104:1655-61.

65 Ndyomugyenyi R, Magnussen P. Chloroquine prophylaxis, iron/folic-acid supplementation or case management of malaria attacks in primigravidae in western Uganda: effects on congenital malaria and infant haemoglobin concentrations. Ann Trop Med Parasitol 2000;94:759-68, discussion 69-70

66 Preziosi P, Prual A, Galan P, Daouda H, Boureima H, Hercberg S. Effect of iron supplementation on the iron status of pregnant women: consequences for newborns. Am $J$ Clin Nutr 1997;66:1178-82.

67 Liu XN, Liu PY. The effectiveness of weekly iron supplementation regimen in improving the iron status of Chinese children and pregnant women. Biomed Environ Sci 1996;9:341-7.

68 Menendez C, Todd J, Alonso PL, Francis N, Lulat S, Ceesay S, et al. The effects of iron supplementation during pregnancy, given by traditional birth attendants, on the prevalence of anaemia and malaria. Trans R Soc Trop Med Hyg 1994;88:590-3.

69 Simmons WK, Cook JD, Bingham KC, Thomas M, Jackson J, Jackson M, et al. Evaluation of a gastric delivery system for iron supplementation in pregnancy. Am J Clin Nutr 1993;58:622-6.

70 Torlesse $\mathrm{H}$, Hodges M. Anthelminthic treatment and haemoglobin concentrations during pregnancy. Lancet 2000;356:1083

71 Suharno D, West CE, Muhilal, Karyadi D, Hautvast JG. Supplementation with vitamin A and iron for nutritional anaemia in pregnant women in West Java, Indonesia. Lancet 1993;342:1325-8

72 Sood SK, Ramachandran K, Mathur M, Gupta K, Ramalingaswamy V, Swarnabai C, et al. W.H.O. sponsored collaborative studies on nutritional anaemia in India: 1 . The effects of supplemental oral iron administration to pregnant women. Q J Med 1975;44:241-58.

73 Ziaei S, Janghorban R, Shariatdoust S, Faghihzadeh S. The effects of iron supplementation on serum copper and zinc levels in pregnant women with high-normal hemoglobin. Int $J$ Gynaecol Obstet 2008;100:133-5.

74 Zeng L, Dibley MJ, Cheng Y, Dang S, Chang S, Kong L, et al. Impact of micronutrient supplementation during pregnancy on birth weight, duration of gestation, and perinatal mortality in rural western China: double blind cluster randomised controlled trial. BMJ 2008;337:a2001.

75 Zhou SJ, Gibson RA, Makrides M. Routine iron supplementation in pregnancy has no effect on iron status of children at six months and four years of age. $J$ Pediatr 2007:151:438-40.

76 Tanumihardjo SA. Vitamin A and iron status are improved by vitamin A and iron supplementation in pregnant Indonesian women. J Nutr 2002;132:1909-12.

77 Finch C. Regulators of iron balance in humans. Blood 1994;84:1697-702.

78 Lipinski P, Stys A, Starzynski RR. Molecular insights into the regulation of iron metabolism during the prenatal and early postnatal periods. Cell Mol Life Sci 2013;70:23-38.

79 Ziaei S, Norrozi M, Faghihzadeh S, Jafarbegloo E. A randomized placebo-controlled tria to determine the effect of iron supplementation on pregnancy outcome in pregnant women with hemoglobin >13.2 g/dL. BJOG 2007;114:684-8.
80 Banhidy F, Acs N, Puho EH, Czeizel AE. Iron deficiency anemia: pregnancy outcomes with or without iron supplementation. Nutrition 2011;27:65-72.

81 Fareh OI, Rizk DE, Thomas L, Berg B. Obstetric impact of anaemia in pregnant women in United Arab Emirates. J Obstet Gynaeco I 2005;25:440-4.

82 El Guindi W, Pronost J, Carles G, Largeaud M, El Gareh N, Montoya Y, et al. [Severe maternal anemia and pregnancy outcome]. $J$ Gynecol Obstet Biol Reprod (Paris) 2004:33:506-9.

83 Chang SC, O'Brien KO, Nathanson MS, Mancini J, Witter FR. Hemoglobin concentrations influence birth outcomes in pregnant African-American adolescents. J Nutr 2003;133:2348-55.

84 Arbuckle TE, Sherman GJ. Comparison of the risk factors for pre-term delivery and intrauterine growth retardation. Paediatr Perinat Epidemiol 1989;3:115-29.

85 Hwang HS, Kim YH, Kwon JY, Park YW. Uterine and umbilical artery Doppler velocimetry as a predictor for adverse pregnancy outcomes in pregnant women with anemia. J Perinat Med 2010;38:467-71.

86 Hamalainen $\mathrm{H}$, Hakkarainen $\mathrm{K}$, Heinonen S. Anaemia in the first but not in the second or third trimester is a risk factor for low birth weight. Clin Nutr 2003;22:271-5.

87 Knottnerus JA, Delgado LR, Knipschild PG, Essed GG, Smits F. Haematologic parameters and pregnancy outcome: a prospective cohort study in the third trimester. J Clin Epidemiol 1990;43:461-6.

88 Klebanoff MA, Shiono PH, Berendes HW, Rhoads GG. Facts and artifacts about anemia and preterm delivery. JAMA 1989;262:511-5.

89 Lee HS, Kim MS, Kim MH, Kim YJ, Kim WY. Iron status and its association with pregnancy outcome in Korean pregnant women. Eur J Clin Nutr 2006:60:1130-5.

90 Levy A, Fraser D, Katz M, Mazor M, Sheiner E. Maternal anemia during pregnancy is an independent risk factor for low birthweight and preterm delivery. Eur J Obstet Gynecol Reprod Biol 2005;122:182-6.

91 Lao TT, Chan LY, Tam KF, Ho LF. Maternal hemoglobin and risk of gestational diabetes mellitus in Chinese women. Obstet Gynecol 2002;99:807-12.

92 Scanlon KS, Yip R, Schieve LA, Cogswell ME. High and low hemoglobin levels during pregnancy: differential risks for preterm birth and small for gestational age. Obstet Gynecol 2000;96:741-8.

93 Nordenvall M, Sandstedt B. Placental lesions and maternal hemoglobin levels: a comparative investigation. Acta Obstet Gynecol Scand 1990;69:127-33.

94 Murphy JF O'Riordan J, Newcombe RG, Coles EC, Pearson JF. Relation of haemoglobin levels in first and second trimesters to outcome of pregnancy. Lancet 1986;1:992-4.

95 Mau G. Hemoglobin changes during pregnancy and growth disturbances in the neonate. J Perinat Med 1977;5:172-7.

96 Von Tempelhoff GF, Heilmann L, Rudig L, Pollow K, Hommel G, Koscielny J. Mean maternal second-trimester hemoglobin concentration and outcome of pregnancy: a population-based study. Clin Appl Thromb Hemost 2008;14:19-28.

97 Little MP, Brocard P. Elliott P. Steer PJ. Hemoglobin concentration in pregnancy and perinatal mortality: a London-based cohort study. Am J Obstet Gynecol 2005:193:220-6.

98 Siega-Riz AM, Adair LS, Hobel CJ. Maternal hematologic changes during pregnancy and the effect of iron status on preterm delivery in a West Los Angeles population. Am J Perinatol 1998;15:515-22.

99 Scholl TO, Hediger ML, Fischer RL, Shearer JW. Anemia vs iron deficiency: increased risk of preterm delivery in a prospective study. Am J Clin Nutr 1992;55:985-8.

100 Williams LA, Evans SF, Newnham JP. Prospective cohort study of factors influencing the relative weights of the placenta and the newborn infant. BMJ 1997;314:1864-8.

101 Andrews NC. Iron homeostasis: insights from genetics and animal models. Nat Rev Genet 2000;1:208-17.

102 Gonzales GF, Steenland K, Tapia V. Maternal hemoglobin level and fetal outcome at low and high altitudes. Am J Physiol Regul Integr Comp Physiol 2009;297:R1477-85.

103 Jehan I, McClure EM, Salat S, Rizvi S, Pasha O, Harris H, et al. Stillbirths in an urban community in Pakistan. Am J Obstet Gynecol 2007;197:257.e1-8.

104 Feresu SA, Harlow SD, Woelk GB. Risk factors for prematurity at Harare Maternity Hospital, Zimbabwe. Int J Epidemiol 2004;33:1194-201.

105 Bondevik GT, Lie RT, Ulstein M, Kvale G. Maternal hematological status and risk of low birth weight and preterm delivery in Nepal. Acta Obstet Gynecol Scand 2001;80:402-8.

106 Conde-Agudelo A, Belizan JM, Diaz-Rossello JL. Epidemiology of fetal death in Latin America. Acta Obstet Gynecol Scand 2000;79:371-8.

107 Agarwal DK, Agarwal KN, Satya K, Agarwal S. Weight gain during pregnancy-a key factor in perinatal and infant mortality. Indian Pediatr 1998;35:733-43.

108 Harrison KA, Lister UG, Rossiter CE, Chong H. Perinatal mortality. Br J Obstet Gynaecol 1985;5:86-99.

109 Zhang Q, Ananth CV, Rhoads GG, Li Z. The impact of maternal anemia on perinatal mortality: a population-based, prospective cohort study in China. Ann Epidemiol 2009;19:793-9.

110 Vijayalaxmi KG, Urooj A. Biochemical profile and outcome in normal and high risk subjects. Ind J Clin Biochem 2009;24:269-74.

111 Marahatta R. Study of anaemia in pregnancy and its outcome in Nepal Medical College Teaching Hospital, Kathmandu, Nepal. Nepal Med Coll J 2007;9:270-4.

112 Ren A, Wang J, Ye RW, Li S, Liu JM, Li Z. Low first-trimester hemoglobin and low birth weight, preterm birth and small for gestational age newborns. Int $J$ Gynaecol Obstet 2007;98:124-8. 
113 Mamun AA, Padmadas SS, Khatun M. Maternal health during pregnancy and perinatal mortality in Bangladesh: evidence from a large-scale community-based clinical trial. Paediatr Perinat Epidemiol 2006;20:482-90

114 Shobeiri F, Begum K, Nazari M. A prospective study of maternal hemoglobin status of Indian women during pregnancy and pregnancy outcome. Nutr Res 2006;26:209-13.

115 Lone FW, Qureshi RN, Emanuel F. Maternal anaemia and its impact on perinatal outcome. Trop Med Int Health 2004;9:486-90.

116 Xiong X, Buekens $P$. Fraser WD, Guo Z. Anemia during pregnancy in a Chinese population. Int J Gynaecol Obstet 2003;83:159-64.

117 Malhotra M, Sharma JB, Batra S, Sharma S, Murthy NS, Arora R. Maternal and perinatal outcome in varying degrees of anemia. Int J Gynecol Obstet 2002;79:93-100.

118 Mola G, Permezel M, Amoa AB, Klufio CA. Anaemia and perinatal outcome in Port Moresby. Aust N Z J Obstet Gynaecol 1999;39:31-34.

119 Zhou LM, Yang WW, Hua JZ, Deng CQ, Tao X, Stoltzfus RJ. Relation of hemoglobin measured at different times in pregnancy to preterm birth and low birth weight in Shanghai, China. Am J Epidemiol 1998;148:998-1006.

120 Allen LH. Biological mechanisms that might underlie iron's effects on fetal growth and preterm birth. J Nutr 2001;131(2S-2):581-9S.

121 Scholl TO. Maternal iron status: relation to fetal growth, length of gestation, and iron endowment of the neonate. Nutr Rev 2011:69(suppl 1):S23-9.

122 Feldman RE, Scholl TJ, Alford JK, Handler WB, Harris CT, Chronik BA. Results for diffusion-weighted imaging with a fourth-channel gradient insert. Magn Reson Med 2011;66:1798-808

123 Rohlfs EM, Zhou Z, Heim RA, Nagan N, Rosenblum LS, Flynn K, et al. Cystic fibrosis carrier testing in an ethnically diverse US population. Clin Chem 2011;57:841-8.

124 World Health Organization. Iron and folate supplementation: standards for maternal and neonatal care. Integrated Management of Pregnancy and Childbirth (IMPAC). Department of Making Pregnancy Safer, WHO, 2007.

125 Institute of Medicine. Iron: dietary reference intakes for vitamin A, vitamin K, arsenic, boron, chromium, copper, iodine, iron, manganese, molybdenum, nickel, silicon, vanadium, and zinc. Insitute of Medicine, 2001:290-393.

126 Yakoob MY, Bhutta ZA. Effect of routine iron supplementation with or without folic acid on anemia during pregnancy. BMC Public Health 2011;11(suppl 3):S21.

127 Sloan NL, Jordan E, Winikoff B. Effects of iron supplementation on maternal hematologic status in pregnancy. Am J Public Health 2002;92:288-93.

128 Andrews NC, Schmidt PJ. Iron homeostasis. Annu Rev Physiol 2007;69:69-85.

129 Andrews NC. Iron metabolism: iron deficiency and iron overload. Annu Rev Genomics Hum Genet 2000;1:75-98.

130 Imdad A, Bhutta Z. Routine iron/folate supplementation during pregnancy: effect on maternal anaemia and birth outcomes. Paediatr Perinat Epidemiol 2012;26(suppl 1):168-77.

131 Zhou SJ, Gibson RA, Crowther CA, Makrides M. Should we lower the dose of iron when treating anaemia in pregnancy? A randomized dose-response trial. Eur J Clin Nutr 2009;63:183-90
132 Milman N, Bergholt T, Eriksen L, Byg KE, Graudal N, Pedersen P, et al. Iron prophylaxis during pregnancy-how much iron is needed? A randomized dose- response study of 20-80 mg ferrous iron daily in pregnant women. Acta Obstet Gynecol Scand 2005;84:238-47.

133 Black RE, Allen LH, Bhutta ZA, Caulfield LE, de Onis M, Ezzati M, et al. Maternal and child undernutrition: global and regional exposures and health consequences. Lance 2008;371:243-60.

134 Bastin J, Drakesmith H, Rees M, Sargent I, Townsend A. Localisation of proteins of iron metabolism in the human placenta and liver. Br J Haematol 2006;134:532-43.

135 McArdle HJ, Lang C, Hayes H, Gambling L. Role of the placenta in regulation of fetal iron status. Nutr Rev 2011;69(suppl 1):S17-22.

136 Gambling L, Czopek A, Andersen HS, Holtrop G, Srai SK, Krejpcio Z, et al. Fetal iron status regulates maternal iron metabolism during pregnancy in the rat. Am J Physiol Regul Integr Comp Physiol 2009;296:R1063-70.

137 Steer PJ. Maternal hemoglobin concentration and birth weight. Am J Clin Nutr 2000;71(5 suppl):1285-7S

138 Oppenheimer SJ, Gibson FD, Macfarlane SB, Moody JB, Harrison C, Spencer A, et al. Iron supplementation increases prevalence and effects of malaria: report on clinical studies in Papua New Guinea. Trans R Soc Trop Med Hyg 1986;80:603-12.

139 Sazawal S, Black RE, Ramsan M, Chwaya HM, Stoltzfus RJ, Dutta A, et al. Effects of routine prophylactic supplementation with iron and folic acid on admission to hospital and mortality in preschool children in a high malaria transmission setting: community-based, randomised, placebo-controlled trial. Lancet 2006;367:133-43.

140 Oppenheimer SJ, Macfarlane SB, Moody JB, Harrison C. Total dose iron infusion, malaria and pregnancy in Papua New Guinea. Trans R Soc Trop Med Hyg 1986;80:818-22.

141 Nacher M, McGready R, Stepniewska K, Cho T, Looareesuwan S, White NJ, et al. Haematinic treatment of anaemia increases the risk of Plasmodium vivax malaria in pregnancy. Trans R Soc Trop Med Hyg 2003;97:273-6.

142 World Health Organization. Global health risks: mortality and burden of disease attributable to selected major risk factors. WHO, 2009 .

\section{Accepted: 20 May 2013}

Cite this as: BMJ 2013;346:f3443

This is an Open Access article distributed in accordance with the Creative Commons Attribution Non Commercial (CC BY-NC 3.0) license, which permits others to distribute, remix, adapt, build upon this work non-commercially, and license their derivative works on different terms, provided the original work is properly cited and the use is non-commercial. See: http://creativecommons.org/licenses/by-nc/3.0/. 


\section{Tables}

Table 1 | Summary of effects of iron use on haematological and pregnancy outcomes

\begin{tabular}{|c|c|c|c|c|c|c|c|c|c|c|}
\hline \multirow{2}{*}{$\begin{array}{l}\text { Haematological } \\
\text { outcomes (in third } \\
\text { trimester or at } \\
\text { delivery) }\end{array}$} & \multicolumn{5}{|c|}{ All trials } & \multirow[b]{2}{*}{$\begin{array}{l}\text { No of } \\
\text { trials }\end{array}$} & \multicolumn{4}{|c|}{ High quality trials } \\
\hline & $\begin{array}{l}\text { No of } \\
\text { trials }\end{array}$ & $\begin{array}{c}\text { WMD or RR }(95 \% \\
\text { Cl) }\end{array}$ & $\begin{array}{c}\text { Significance } \\
\text { of effect ( } P \\
\text { value) }\end{array}$ & $\begin{array}{c}\text { Test for } \\
\text { heterogeneity } \\
\text { (P value) }\end{array}$ & $I^{2}(\%)$ & & $\begin{array}{l}\text { WMD or RR }(95 \% \\
\text { Cl) }\end{array}$ & $\begin{array}{c}\text { Significance } \\
\text { of effect ( } P \\
\text { value) }\end{array}$ & $\begin{array}{c}\text { Test for } \\
\text { heterogeneity } \\
\text { (P value) }\end{array}$ & $I^{2}(\%)$ \\
\hline Haemoglobin $(g / L)$ & 36 & 4.59 (3.72 to 5.46$)$ & $<0.001$ & 0.98 & 0 & 15 & 4.20 (3.17 to 5.22 ) & $<0.001$ & 0.95 & 0 \\
\hline Anaemia & 19 & $0.50(0.42$ to 0.59$)$ & $<0.001$ & $<0.001$ & 83 & 8 & $0.66(0.57$ to 0.76$)$ & $<0.001$ & $<0.001$ & 72 \\
\hline Iron deficiency & 8 & $0.59(0.44$ to 0.79$)$ & $<0.001$ & $<0.001$ & 79 & 5 & $0.70(0.55$ to 0.91$)$ & $<0.001$ & 0.001 & 79 \\
\hline $\begin{array}{l}\text { Iron deficiency } \\
\text { anaemia }\end{array}$ & 6 & $0.40(0.26$ to 0.60$)$ & $<0.001$ & 0.18 & 33 & 4 & - & - & - & - \\
\hline \multicolumn{11}{|l|}{ Pregnancy outcomes } \\
\hline Birth weight (g) & 19 & $\begin{array}{c}41.21(1.20 \text { to } \\
81.23)\end{array}$ & $<0.001$ & $<0.001$ & 99 & 12 & $\begin{array}{c}68.67 \text { (37.67 to } \\
99.68) \\
\end{array}$ & $<0.001$ & $<0.001$ & 97 \\
\hline Low birth weight & 13 & $0.81(0.71$ to 0.93$)$ & 0.001 & 0.44 & 1 & 7 & $0.82(0.72$ to 0.94$)$ & 0.003 & 0.15 & 37 \\
\hline $\begin{array}{l}\text { Gestational age } \\
\text { (weeks) }\end{array}$ & 10 & $0.11(-0.35$ to 0.57$)$ & 0.64 & 1.00 & 0 & 6 & $\begin{array}{c}0.12(-0.36 \text { to } 0.60 \\
)\end{array}$ & 0.63 & 1.00 & 0 \\
\hline Preterm birth & 12 & 0.84 (0.68 to 1.03$)$ & 0.09 & 0.68 & 0 & 9 & 0.84 (0.68 to 1.05$)$ & 0.12 & 0.67 & 0 \\
\hline $\begin{array}{l}\text { Small for gestational } \\
\text { age birth }\end{array}$ & 8 & 0.85 (0.67 to 1.08$)$ & 0.17 & 0.02 & 59 & 6 & $0.84(0.62$ to 1.14$)$ & 0.26 & 0.005 & 70 \\
\hline Birth length $(\mathrm{cm})$ & 8 & $\begin{array}{c}-1.08(-4.97 \text { to } \\
2.80)\end{array}$ & 0.58 & 0.76 & 0 & 6 & $\begin{array}{c}-1.15(-5.15 \text { to } \\
2.84)\end{array}$ & 0.58 & 0.41 & 0 \\
\hline
\end{tabular}

$\mathrm{RR}=$ relative risk; $\mathrm{WMD}=$ weighted mean difference. 
Table 2| Subgroup analysis for effect of iron use on haemoglobin concentration in third trimester or at delivery (g/L)

\begin{tabular}{|c|c|c|c|c|}
\hline Characteristic & No of trials & Mean difference $(95 \% \mathrm{Cl})$ & Significance of effect (P value) & Test for interaction ( $P$ value) \\
\hline \multicolumn{4}{|l|}{ Country: } & \multirow[t]{3}{*}{0.003} \\
\hline Low or middle income & 14 & 8.34 (5.69 to 11.00$)$ & $<0.001$ & \\
\hline High income & 22 & 4.13 (3.21 to 5.06$)$ & $<0.001$ & \\
\hline \multicolumn{4}{|l|}{ Malaria endemicity: } & \multirow[t]{3}{*}{0.087} \\
\hline Endemic & 7 & 8.16 (3.98 to 12.34$)$ & $<0.001$ & \\
\hline Non-endemic & 29 & 4.43 (3.53 to 5.32$)$ & $<0.001$ & \\
\hline \multicolumn{4}{|l|}{ Baseline anaemia: } & \multirow[t]{3}{*}{0.005} \\
\hline Anaemic & 7 & $10.17(6.14$ to 14.19$)$ & $<0.001$ & \\
\hline Non-anaemic & 26 & 4.29 (3.39 to 5.19$)$ & $<0.001$ & \\
\hline \multicolumn{4}{|l|}{ Start of iron use: } & \multirow[t]{3}{*}{0.086} \\
\hline Early ( $\leq 21$ weeks' gestation) & 32 & 4.48 (3.60 to 5.36$)$ & $<0.001$ & \\
\hline Late ( $>22$ weeks' gestation) & 4 & 9.73 (3.80 to 15.66$)$ & $<0.001$ & \\
\hline
\end{tabular}


Table 3| Subgroup analysis and meta-regression for effect of iron use on maternal anaemia in third trimester or at delivery

\begin{tabular}{|c|c|c|c|c|c|}
\hline \multirow[b]{2}{*}{ Characteristic } & \multirow[b]{2}{*}{ No of trials } & \multirow[b]{2}{*}{ Relative risk $(95 \% \mathrm{Cl})$} & \multicolumn{3}{|c|}{ Univariate meta-regression } \\
\hline & & & $\begin{array}{l}\mathrm{P} \text { value for test for } \\
\text { heterogeneity by covariate }\end{array}$ & $\begin{array}{c}\text { Residual } I^{2} \text { after } \\
\text { adjustment for covariate } \\
(\%)\end{array}$ & $\begin{array}{c}\text { Reduction in } \mathrm{I}^{2} \text { after } \\
\text { adjustment for covariate } \\
(\%)\end{array}$ \\
\hline Country: & & & 0.009 & 82 & 1 \\
\hline Low or middle income & 8 & $0.58(0.50$ to 0.67$)$ & & & \\
\hline High income & 11 & $0.23(0.12$ to 0.45$)$ & & & \\
\hline Malaria endemicity: & & & 0.003 & 79 & 5 \\
\hline Endemic & 6 & 0.61 (0.53 to 0.71$)$ & & & \\
\hline Non-endemic & 13 & $0.30(0.19$ to 0.46$)$ & & & \\
\hline Baseline anaemia: & & & 0.008 & 74 & 10 \\
\hline Anaemic & 5 & $0.60(0.51$ to 0.71$)$ & & & \\
\hline Non-anaemic & 12 & $0.32(0.21$ to 0.50$)$ & & & \\
\hline Start of iron use: & & & 0.60 & 84 & 0 \\
\hline Early ( $\leq 21$ weeks of gestation) & 13 & 0.50 (0.39 to 0.65$)$ & & & \\
\hline Late (>22 weeks of gestation) & 6 & $0.45(0.33$ to 0.61$)$ & & & \\
\hline
\end{tabular}


Table 4| Summary of exposure-response relations with haematological and birth outcomes (trials)

Exposure: increase in iron dose $(10 \mathrm{mg} / \mathrm{day}) \quad$ No of trials WMD or RR $(95 \% \mathrm{Cl}) \quad \mathrm{P}$ value

Maternal anaemia

\begin{tabular}{llll}
\hline All trials & 18 & $0.99(0.990$ to 0.995$)$ & $<0.001$ \\
\hline All trials (excluding trial with iron dose $900 \mathrm{mg} /$ day $)$ & 17 & $0.93(0.91$ to 0.94$)$ & $<0.001$ \\
\hline Trials with iron dose up to $66 \mathrm{mg} / \mathrm{day}$ & 11 & $0.88(0.84$ to 0.92$)$ & $<0.001$ \\
\hline Low birth weight & 13 & $0.97(0.95$ to 0.98$)$ & $<0.001$ \\
\hline All trials & 11 & $0.96(0.95$ to 0.98$)$ & $<0.001$ \\
\hline Trials with iron dose up to $66 \mathrm{mg} / \mathrm{day}$ & & & \\
\hline Birth weight & 18 & $15.10(6.00$ to 24.20$)$ & 0.005 \\
\hline All trials & 14 & $16.70(7.29$ to 26.11$)$ & 0.004 \\
\hline Trials with iron dose up to $66 \mathrm{mg} / \mathrm{day}$ & & & \\
\hline Preterm birth & 12 & $0.99(0.95$ to 1.04$)$ & 0.67 \\
\hline All trials & 11 & $0.99(0.95$ to 1.03$)$ & 0.50 \\
\hline Trials with iron dose up to $66 \mathrm{mg} / \mathrm{day}$ & & &
\end{tabular}

$\mathrm{RR}=$ relative risk; $\mathrm{WMD}=$ weighted mean difference. 
Table 5| Summary of exposure-response relations of haemoglobin difference* $(1 \mathrm{~g} / \mathrm{L})$ in prenatal period with birth outcomes (trials)

\begin{tabular}{lccc} 
Outcomes & No of trials & WMD or RR (95\% Cl) & P value \\
Low birth weight & 11 & $0.96(0.84$ to 1.09$)$ & 0.21 \\
\hline Birth weight & 16 & $14.00(6.80$ to 21.80$)$ & 0.002 \\
\hline Preterm birth & 8 & $0.99(0.94$ to 1.04$)$ & 0.70 \\
\hline
\end{tabular}

$\mathrm{RR}=$ relative risk; $\mathrm{WMD}=$ weighted mean difference.

*Difference in mean haemoglobin concentration between intervention and control groups in included studies. 
Table 6| Summary estimates of anaemia, irrespective of time of anaemia assessment, on pregnancy outcomes (cohort studies)

\begin{tabular}{|c|c|c|c|c|c|c|c|c|c|c|}
\hline \multirow[b]{2}{*}{ Outcome } & \multicolumn{5}{|c|}{ Unadjusted estimates } & \multicolumn{5}{|c|}{ Adjusted estimates } \\
\hline & $\begin{array}{l}\text { No of } \\
\text { studies }\end{array}$ & $\begin{array}{c}\text { Crude OR or MD* } \\
(95 \% \mathrm{Cl})\end{array}$ & $\begin{array}{c}\text { Significance } \\
\text { of effect ( } P \\
\text { value) }\end{array}$ & $\begin{array}{c}\text { Test for } \\
\text { heterogeneity } \\
\text { ( } \mathrm{P} \text { value) }\end{array}$ & $I^{2}(\%)$ & $\begin{array}{l}\text { No of } \\
\text { studies }\end{array}$ & $\begin{array}{l}\text { Adjusted OR or } \\
\text { MD }(95 \% \mathrm{Cl})\end{array}$ & $\begin{array}{c}\text { Significance } \\
\text { of effect ( } P \\
\text { value) }\end{array}$ & $\begin{array}{c}\text { Test for } \\
\text { heterogeneity } \\
\text { (P value) }\end{array}$ & $I^{2}(\%)$ \\
\hline Birth weight & 9 & $\begin{array}{c}-20.15(-60.91 \text { to } \\
20.61)\end{array}$ & 0.33 & $<0.001$ & 70 & 0 & - & - & - & - \\
\hline Low birth weight & 25 & 1.25 (1.08 to 1.45$)$ & 0.003 & $<0.001$ & 90 & 9 & $\begin{array}{c}1.13(0.95 \text { to } \\
1.35)\end{array}$ & $<0.001$ & $<0.001$ & 86 \\
\hline Gestational age & 6 & $\begin{array}{c}-0.37(-0.74 \text { to } \\
-0.00)\end{array}$ & 0.05 & $<0.001$ & 81 & 0 & - & - & - & - \\
\hline Preterm birth & 26 & $1.28(1.12$ to 1.47$)$ & $<0.001$ & $<0.001$ & 89 & 13 & $\begin{array}{c}1.28(1.11 \text { to } \\
1.48)\end{array}$ & 0.001 & $<0.001$ & 83 \\
\hline $\begin{array}{l}\text { Small for } \\
\text { gestational age }\end{array}$ & 13 & $1.04(0.80$ to 1.35$)$ & 0.77 & $<0.001$ & 92 & 9 & $\begin{array}{c}1.08(0.90 \text { to } \\
1.29)\end{array}$ & 0.43 & $<0.001$ & 88 \\
\hline Stillbirth & 12 & 1.19 (1.09 to 1.29$)$ & $<0.001$ & 0.21 & 24 & 2 & - & - & - & - \\
\hline $\begin{array}{l}\text { Perinatal } \\
\text { mortality }\end{array}$ & 8 & $1.03(0.77$ to 1.37$)$ & 0.86 & 0.003 & 67 & 2 & - & - & - & - \\
\hline
\end{tabular}

$\mathrm{MD}=$ mean difference; $\mathrm{OR}=\mathrm{odd}$ ratio. 


\section{Figures}

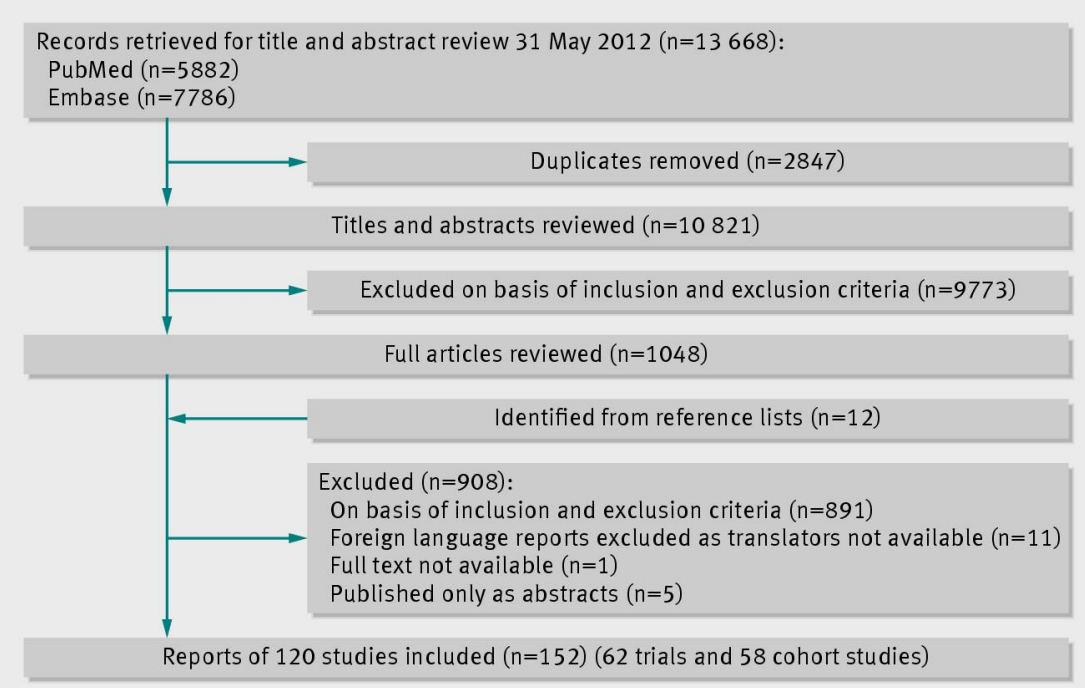

Fig 1 Flow diagram of identification process for eligible studies 


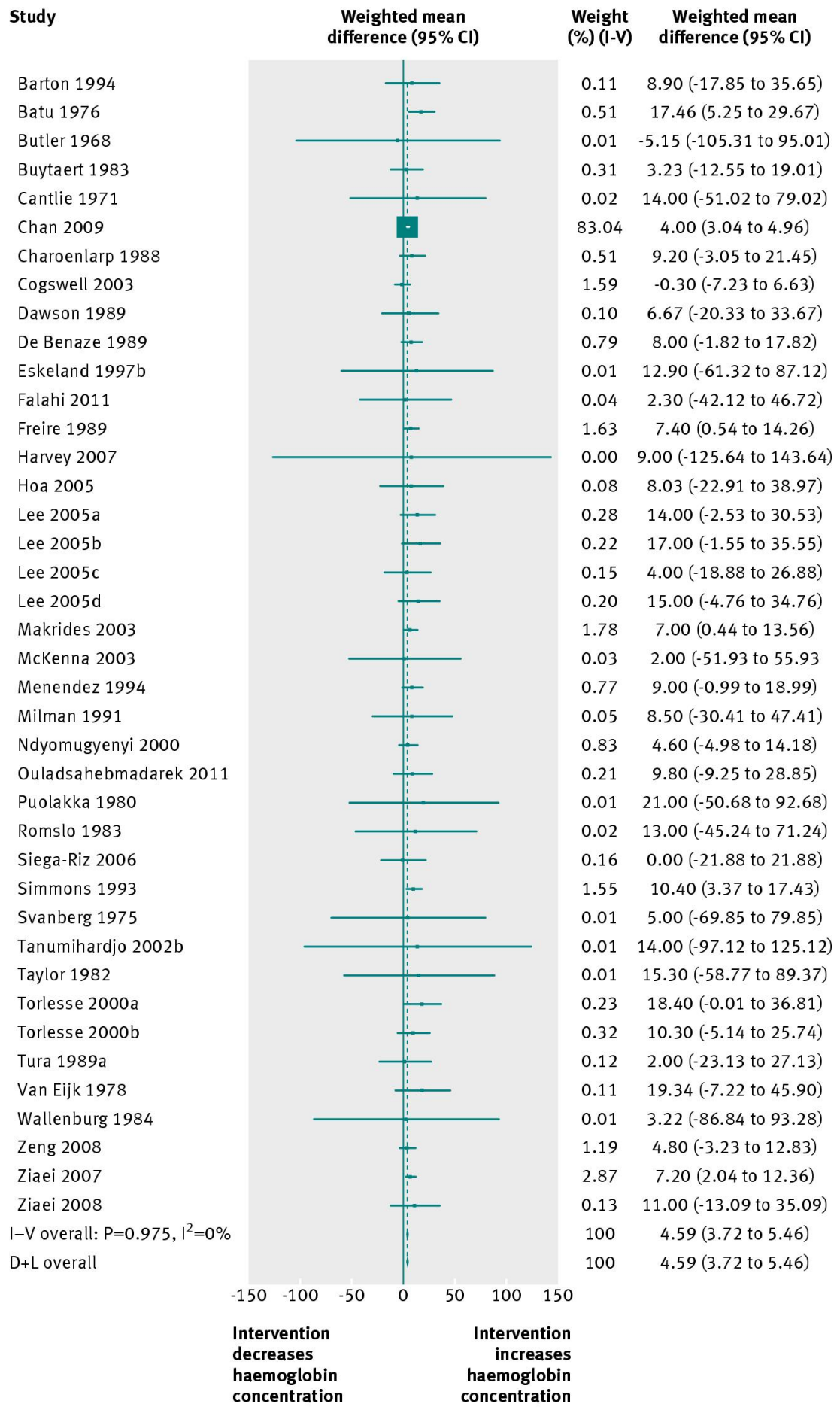

Fig 2 Forest plot for effect of iron use on mean haemoglobin concentration $(\mathrm{g} / \mathrm{L})$ in third trimester or at delivery. $\mathrm{I}-\mathrm{V}=\mathrm{inverse}$ variance method; $\mathrm{D}+\mathrm{L}=$ DerSimonian and Laird method 


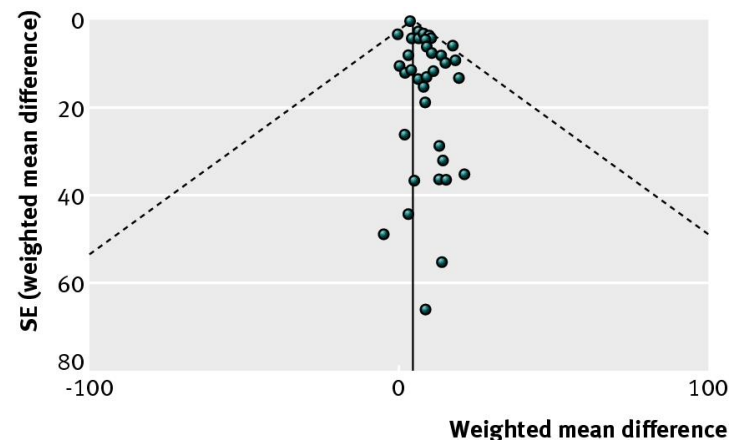

Fig 3 Funnel plot (with pseudo 95\% confidence limits) for effect of iron use on mean haemoglobin concentration ( $\mathrm{g} / \mathrm{L}$ ) in third trimester or at delivery

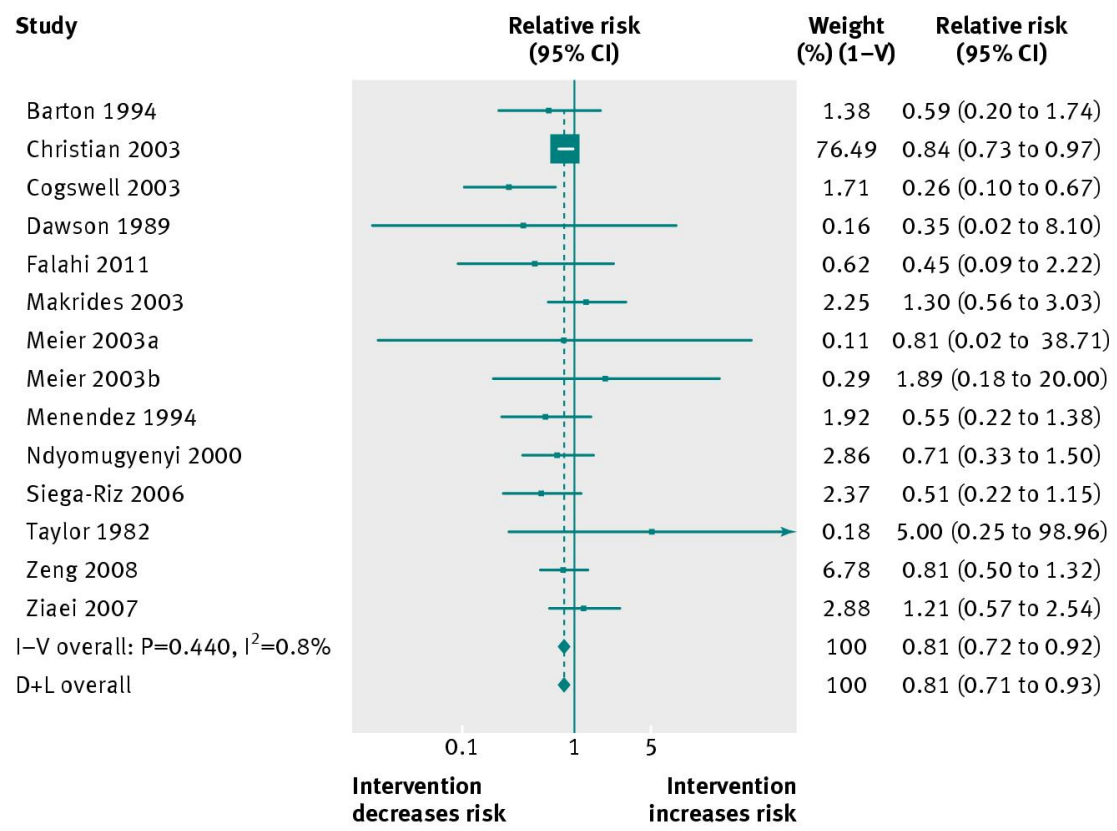

Fig 4 Forest plot for effect of iron use on low birth weight. $I-V=$ =inverse variance method; $D+L=D e r S i m o n i a n$ and Laird method 